\title{
Sorafenib in metastatic uveal melanoma: efficacy, toxicity and health-related quality of life in a multicentre phase II study
}

\author{
F Mouriaux ${ }^{\star}, 1,2,3,4$, V Servois ${ }^{5}$, J J Parienti ${ }^{4}$, T Lesimple $^{6}$, A Thyss $^{7}$, C Dutriaux ${ }^{8}$, E M Neidhart-Berard ${ }^{9}$,
} N Penel ${ }^{10}, C_{\text {Delcambre }}{ }^{11}$, L Peyro Saint Paul ${ }^{4}$, A D Pham ${ }^{4}, \mathrm{~N} \mathrm{Heutte}^{11}$, S Piperno-Neumann ${ }^{12}$ and F Joly ${ }^{4,11}$

${ }^{1}$ Service d'ophtalmologie (Department of Ophthalmology), CHU Rennes, 35033 Rennes, France; ${ }^{2}$ Faculté de Médecine (Faculty of Medicine), Université de Rennes 1, F35043 Rennes, France; ${ }^{3}$ Centre universitaire d'ophtalmologie-Recherche (OphthalmologyResearch University Centre), Hôpital du Saint-Sacrement, Centre de Recherche du CHU de Québec (CHU Quebec Research Centre), G1S 4 L8 Québec, Canada; ${ }^{4} \mathrm{CHU}$ Caen, F-14033 Caen France; ${ }^{5}$ Institut Curie, Département d'Imagerie Médicale (Curie Institute, Department of Medical Imaging), F-75005 Paris, France; ${ }^{6}$ Centre Eugène Marquis, F-35000 Rennes, France; ${ }^{7}$ Centre Antoine Lacassagne, F-06000 Nice, France; ${ }^{8}$ Service Dermatologie (Dermatology Department), CHU de Bordeaux, F-33000 Bordeaux, France; ${ }^{9}$ Centre Léon Bérard, F-69000 Lyon, France; ${ }^{10}$ Centre Oscar Lambret, F-59000 Lille, France; ${ }^{11}$ Centre François Baclesse, F-14000 Caen France and ${ }^{12}$ Département d'Oncologie Médicale, Institut Curie, (Department of Medical Oncology, Curie Institute), 75005 Paris, France

Background: The aim of the study was to analyse efficacy, safety, and health-related quality of life (HRQoL) for sorafenib treatment in patients with metastatic uveal melanoma.

Methods: A multicentre, single-arm phase II trial was conducted. The primary objective was to determine the non-progression rate (RECIST) at 24 weeks for patients receiving sorafenib at a dose of $800 \mathrm{mg}$ per day. Secondary endpoints included progressionfree survival (PFS), overall survival (OS), toxicity, and HRQoL.

Results: Thirty-two patients were included. Ten patients showed non-progression at 24 weeks (31.2\%) without objective tumour responses. The estimated 24-week PFS was 31.2\% (95\% Cl: 14.8\%-47.6\%) and the estimated 24-week OS was $62.5 \%(95 \% \mathrm{Cl}$ : 45.4\%-79.6\%). Ten patients (34.3\%) had at least one grade 3 or 4 adverse reaction and 12 patients (41.4\%) required dose modifications due to toxicity. At 24 weeks, no patient had an improvement in global HRQoL and $87.5 \%$ experienced a permanent increase in physical fatigue.

Conclusions: Sorafenib demonstrated non-progression at 24 weeks in $31.2 \%$ of patients. However, $41.4 \%$ of patients required dose modifications due to toxicity and no improvement in HRQOL was demonstrated.

Despite adequate local treatment, metastatic uveal melanoma (MUM)-related mortality is $31 \%$ at 5 years and $45 \%$ at 15 years, and is highly dependent on disease progression in the liver (Kujala et al, 2003). Median survival after diagnosis, for patients with liver metastases, is $\sim 4-6$ months with a 1-year survival rate in 10-15\% of cases (Gragoudas et al, 1991). Patients with non-liver-related metastases have a median survival rate of 19-28 months with a 1-year survival rate in $76 \%$ of cases (Woodman, 2012).

Systemic treatment for MUM is considered to be ineffective (Woodman, 2012). Sorafenib (BAY439006, Nexavar, Bayer Pharmaceuticals, Berlin, Germany), a 3-thienyl urea derivative, is an oral multikinase inhibitor that inhibits tumour growth by acting on the tumour and tumour vasculature cells. Clinical trials

*Correspondence: Professor F Mouriaux; E-mail: frederic.mouriaux@chu-rennes.fr

Received 11 November 2015; revised 31 March 2016; accepted 6 April 2016; published online 2 June 2016

(c) 2016 Cancer Research UK. All rights reserved 0007-0920/16 
evaluating sorafenib as a single agent in patients with advanced solid tumours have also already demonstrated efficacy, especially in renal cell carcinoma and hepatocellular carcinoma (Escudier et al, 2009). Preclinical studies suggest that, besides inhibiting ERK phosphorylation, sorafenib may have a potential beneficial effect on uveal melanoma cell proliferation (Calipel et al, 2003; Babchia et al, 2008; Mitsiades et al, 2011).

The aim of this study was to evaluate the non-progression rate at 24 weeks for patients with MUM treated with sorafenib at a dose of $800 \mathrm{mg}$ per day. Secondary endpoints included progression-free survival (PFS), overall survival (OS), toxicity, and health-related quality of life (HRQoL).

\section{MATERIAL AND METHODS}

Study investigations were performed following approval by the local Ethics Committee and National Human Investigations Committees (EudraCT: 2010-022527-29). Written informed consent was obtained from each patient. The study started in March 2012 and ended in October 2013. Patient eligibility is listed in Supplementary Information 1.

Investigational treatment. Patients received $400 \mathrm{mg}$ twice a day (800 mg daily) of sorafenib until disease progression or unacceptably severe toxicity occurred during treatment, or an individual decision was made. Up to two dose reductions (to $200 \mathrm{mg}$ daily) were allowed according to grade 2 or 3 toxicities. Restaging radiological evaluation was performed at baseline and then every 8 weeks during the sorafenib treatment period by comparing unidimensional measurements via liver MRI and/or thoracoabdominopelvic CT scans. Two reviewers, including one senior radiologist, independently evaluated all imaging data and reached a consensus. Disease progression was evaluated by the investigators using Response Evaluation Criteria In Solid Tumors (RECIST) criteria version 1.1 (NIH, Bethesda, MD, USA) and had to be confirmed with subsequent radiological evaluation at least 4 weeks after the previous evaluation (Dancey et al, 2009). Patients were monitored for toxicity weekly during the first therapy cycle and then before each therapy cycle. Adverse drug reactions (ARs) reported in the Investigational Brochure (Section 5.3.3.2 version 14.0 April 2014) were used to determine the likelihood of ARs during the study. Toxicities were reported using Common Terminology Criteria for Adverse Events version $4.0(\mathrm{NIH})$.

Health-related quality of life was evaluated before treatment, on week 4 , week 8 , week 16 , and week 24 . The patients completed the self-reported Functional Assessment of Cancer Therapy General questionnaire (FACT-G version 4). The FACT-G item scales are scored according to four categories: physical, emotional, social, and functional well-being (http://www.facit. org/FACITOrg/Questionnaires), with higher scores reflecting better quality of life (Cella et al, 1993). The Multidimensional Fatigue Inventory-20 self-reported questionnaire covers five categories: general fatigue, physical fatigue, mental fatigue, reduced motivation, and reduced activity. Each dimension scale ranges from 0 to 100 , the score increasing with the level of fatigue (Smets et al, 1995).

Statistical methods. We conducted a single-arm phase II trial with the rate of non-progression at 24 weeks with the following statistical assumption: $P_{0}=10 \%, P_{1}=30 \%$, alpha risk of $5 \%$ and $80 \%$ power. At least six patients with non-progression at 24 weeks were required to reject the null hypothesis (Supplementary Information 2). The analysis followed an intent-to-treat approach, including all patients starting Sorafenib.

Clinically relevant improvement or decline of HRQoL or fatigue was defined as a difference of $10 \%$ in the maximum change from baseline (Osoba and Zee, 1998). The time to definitive deterioration of HRQoL for a patient was a period between inclusion and deterioration of at least $10 \%$, confirmed in all the other evaluations (Anota et al, 2015). Deaths were considered as censored data.

Statistical analysis was performed using the SAS v9.4 software (SAS software, Cary, NC, USA).

\section{RESULTS}

Patient characteristics and treatment administration. A total of 32 patients (mean age 66.8 years $\pm 8.4,16$ men and 13 women) were enrolled in the study. The patients' demographic data at inclusion is shown in Table 1.

Efficacy. Ten patients (31.2\%) showed non-progression at 24 weeks. There were no confirmed objective tumour responses according to RECIST: no patient had $>10 \%$ of tumour burden regression after 6 months of treatment. The estimated 24-week PFS was $31.2 \%$ (95\% CI: $14.8 \%-47.6 \%)$ and the estimated 24 -week OS was $62.5 \%$ (95\% CI: $45.4 \%-79.6 \%$ ) (Figure 1). The OS rate among patients who received at least 2 months of treatment $(n=29)$ in this trial analysis did not significantly differ compared with the expected patient survival rate using the one-sample log-rank test $(P>0.05)$. Moreover, efficacy on systemic therapy-naive versus previously treated patients did not show any significant difference $(P>0.20)$.

Toxicity. Two hundred and eighty-one adverse reactions (ARs) were reported, including 20 grade 3 or 4 ARs reported in 10 patients (Supplementary Table 1). One patient with a hand-footskin reaction discontinued the protocol therapy due to toxicity at 4 weeks. Twelve patients (41.4\%) required dose modifications due to toxicity. Ten patients received $400 \mathrm{mg}$ per day and 2 patients received $200 \mathrm{mg}$ per day.

Health-related quality of life. Fatigue and HRQoL scores are reported in Table 2. Six of the $25(24 \%)$ patients showed a significant clinical improvement in the general quality of life after 8 weeks of treatment. However, 7 (28\%) and $18(72 \%)$ patients had a significant decline in global HRQoL and increasing general fatigue, respectively. At 24 weeks, no patients had a

\begin{tabular}{|c|c|}
\hline $\begin{array}{l}\text { Median of time from diagnosis of primary tumour } \\
\text { to diagnosis of metastasis }\end{array}$ & 34.5 Months $(0-365)$ \\
\hline $\begin{array}{l}\text { Median of time from diagnosis of metastasis to first } \\
\text { line of treatment }\end{array}$ & 4.9 Months (0-8) \\
\hline \multicolumn{2}{|l|}{ Performance status (ECOG) } \\
\hline $\begin{array}{l}0(\%) \\
1(\%) \\
2(\%)\end{array}$ & $\begin{array}{c}15(46.9) \\
16(50.0) \\
1(3.1)\end{array}$ \\
\hline Mean of number of localisation by patient (range) & 1.68 (s.d. 0.96) \\
\hline \multicolumn{2}{|l|}{ Localisation metastases } \\
\hline $\begin{array}{l}\text { Liver (\%) } \\
\text { Bone (\%) } \\
\text { Lung (\%) } \\
\text { Other (\%) }\end{array}$ & $\begin{array}{r}29(90.6) \\
7(21.8) \\
10(31.8) \\
8(25.0)\end{array}$ \\
\hline \multicolumn{2}{|l|}{ Prior systemic treatment } \\
\hline $\begin{array}{l}\text { None (\%) } \\
\text { One line of systematic chemotherapy (\%) } \\
\text { Two lines of systematic chemotherapy (\%) } \\
\text { Intra-haematic chemo-embolisation (\%) }\end{array}$ & $\begin{aligned} 19 & (59.3) \\
5 & (15.6) \\
7 & (22.0) \\
1 & (3.0)\end{aligned}$ \\
\hline
\end{tabular}



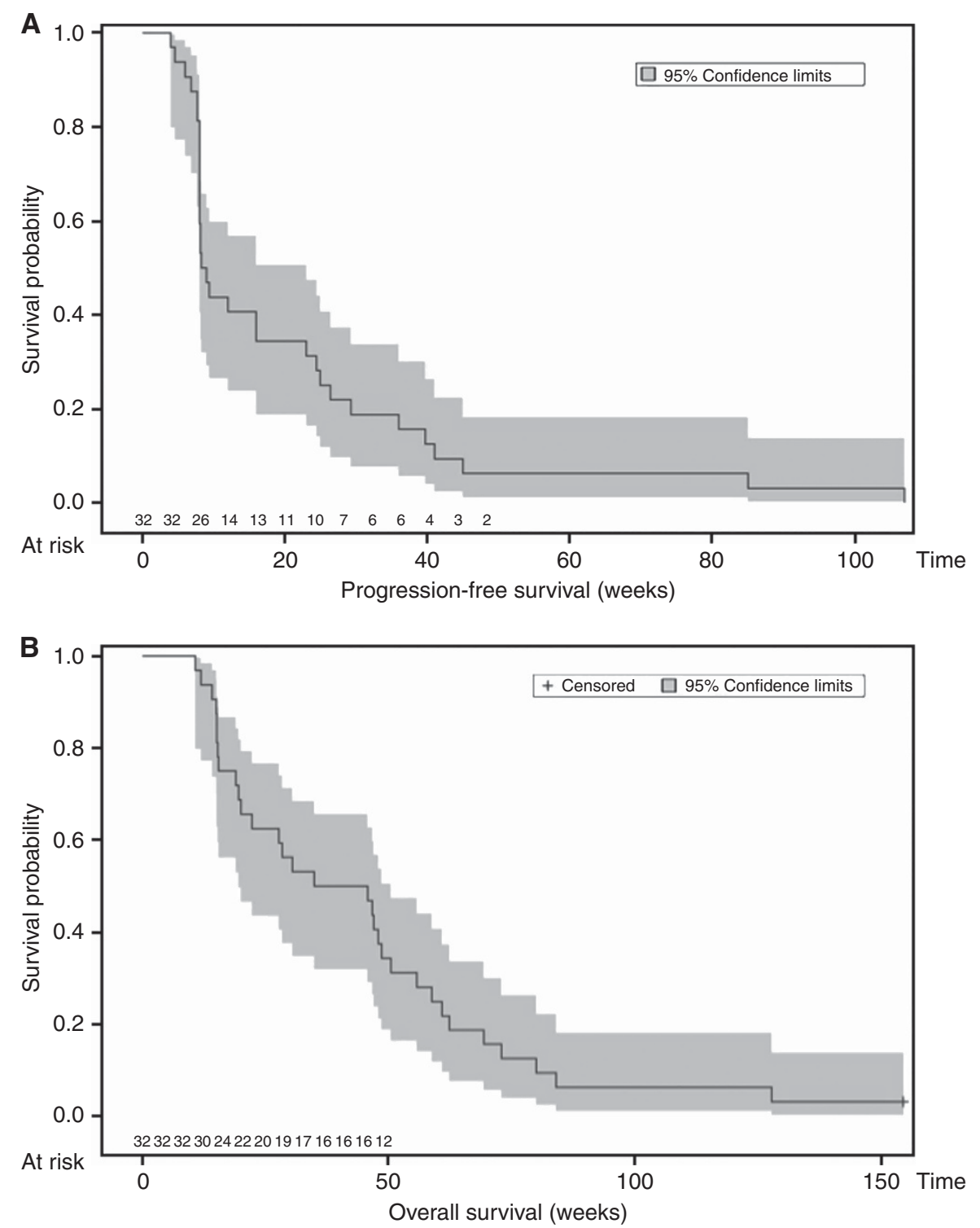

Figure 1. Kaplan-Meier curve for PFS (A) and OS (B) $(n=32)$.

Table 2. Scores of cancer therapy general questionnaire (FACT-G) and MFI questionnaire (MFI-20) during the 24 weeks study period

\begin{tabular}{|c|c|c|c|c|c|}
\hline & $\begin{array}{l}\text { T0 }(n=32) \\
\text { Mean }(\mathrm{Std})\end{array}$ & $\begin{array}{c}\text { Week } 4(n=28) \\
\text { Mean }(\text { Std })\end{array}$ & $\begin{array}{c}\text { Week } 8(n=25) \\
\text { Mean }(\text { Std })\end{array}$ & $\begin{array}{c}\text { Week } 16(n=13) \\
\text { Mean }(\text { Std })\end{array}$ & $\begin{array}{c}\text { Week } 24(n=8) \\
\text { Mean }(S t d)\end{array}$ \\
\hline \multicolumn{6}{|l|}{ FACT G } \\
\hline Social/family well-being & $22 \pm 5$ & $20 \pm 5$ & $21 \pm 4$ & $20 \pm 4$ & $21 \pm 5$ \\
\hline Emotional well-being & $16 \pm 5$ & $17 \pm 4$ & $17 \pm 4$ & $16 \pm 5$ & $17 \pm 5$ \\
\hline Functional well-being & $18 \pm 5$ & $17 \pm 5$ & $16 \pm 5$ & $15 \pm 6$ & $16 \pm 3$ \\
\hline Global score Fact-G & $81 \pm 15$ & $75 \pm 16$ & $74 \pm 13$ & $72 \pm 17$ & $74 \pm 14$ \\
\hline General fatigue & $34 \pm 26$ & $47 \pm 27$ & $53 \pm 22$ & $42 \pm 22$ & $43 \pm 22$ \\
\hline Physical fatigue & $29 \pm 27$ & $46 \pm 30$ & $50 \pm 23$ & $41 \pm 27$ & $43 \pm 26$ \\
\hline Mental fatigue & $21 \pm 21$ & $27 \pm 24$ & $31 \pm 24$ & $19 \pm 18$ & $22 \pm 18$ \\
\hline Reduced activity & $31 \pm 22$ & $42 \pm 28$ & $51 \pm 23$ & $34 \pm 23$ & $44 \pm 27$ \\
\hline Reduced motivation & $28 \pm 19$ & $34 \pm 25$ & $39 \pm 23$ & $30 \pm 20$ & $34 \pm 23$ \\
\hline
\end{tabular}

definitive improvement in HRQoL. Seven patients (87.5\%) had a definitive increase in physical fatigue. The median times of definitive deterioration of physical well-being and general fatigue were 16 weeks $([4 ; \infty[)$ and 8 weeks $([4 ; \infty[)$ respectively. There was no link between diarrhoea and the different dimensions of HRQoL $(P>0.05)$. 


\section{DISCUSSION}

We report the results of the first phase II clinical trial investigating the activity of sorafenib monotherapy in patients with MUM. Of the 32 patients enrolled in the study, $31.2 \%$ experienced stable disease at 24 months. However, compared with the expected survival rate predicted by the Korn model, this achievement did not translate into significant survival benefit (Korn et al, 2010). Although accounting for risk factors, it should be remembered that the relevance of the Korn meta-analysis for uveal melanoma patients is unknown at this time. Interestingly, two patients had a prolonged clinical benefit from sorafenib but we did not have the status of the BRAF mutation in metastatic lesions. Our data for sorafenib appears quite similar to that obtained with the sunitinib c-kit inhibitors and the MEK inhibitor, Selumetinib, which modestly improved in PFS without improvement in OS (Mahipal et al, 2012; Carvajal et al, 2014). Moreover, sorafenib in combination with carboplatin plus paclitaxel, also showed no objective responses (Bhatia et al, 2012).

In the present analysis, the safety profile of sorafenib monotherapy is as expected (Di Marco et al, 2013). In the present report, tolerability of sorafenib is the major concern, with grade 3 and 4 ARs occurring in one third of patients and dose reduction in $40 \%$ of patients. The high rate of massive liver involvement and inherent alteration of liver functions could explain the poor tolerability of sorafenib in MUM patients. As described in other studies, the most common sorafenib-associated ARs are dermatological lesions and diarrhoea. However, we found that diarrhoea did not have a direct impact on global HRQoL.

HRQoL analysis has not been reported in previous studies of MUM. Composite endpoints including HRQoL are a priority in this type of study, reflecting the real clinical benefit of the treatment, especially in this situation when cure is not possible and PFS is not adequately defined by the clinical effects (Wilson et al, 2015). As sorafenib is an oral medication, HRQoL may be better than when using intravenous chemotherapy. However, our study was not a randomised study and this question remains unresolved. The major self-reported symptom was fatigue, with $72 \%$ and $87.5 \%$ of patients experiencing a significant increase in fatigue after 8 weeks and 24 weeks of treatment, respectively, which confirms what has already been observed at other tumour sites (Larkin et al, 2010). Cancer-related fatigue is a multifactorial condition that affects cancer patients before the start of therapy. It increases during therapy and can persist thereafter. The management strategies for preventing or reducing the severity of targeted therapy-related fatigue described in the literature are experiencebased rather than evidence-based (Berger et al, 2015). Dose reductions may be considered in the event of grade 3 or 4 fatigue (Méndez-Vidal et al, 2012).

Sorafenib induces stable disease in advanced uveal melanoma, but with significant toxicity and without improvement of the quality of life. In our opinion, a phase III study would not be necessary. However, further clinical evaluation may be refined to select patients for such treatment. As sorafenib and other tyrosine kinase inhibitors have failed to improve the OS of metastatic UM patients, further studies should focus their attention on immunotherapy.

\section{ACKNOWLEDGEMENTS}

We are grateful to Caroline Henry-Seree and Sylvie Brucato for helping with file management. We also extend our grateful thanks to Fabien Chaillot for all legal procedures and to Professor Sylvie Negrier for her participation in the study. This study was supported by grant DGOS/PHRC09_06-005.

\section{CONFLICT OF INTEREST}

The authors declare no conflict of interest.

\section{REFERENCES}

Anota A, Hamidou Z, Paget-Bailly S, Chibaudel B, Bascoul-Mollevi C, Auquier P, Westeel V, Fiteni F, Borg C, Bonnetain F (2015) Time to health-related quality of life score deterioration as a modality of longitudinal analysis for health-related quality of life studies in oncology: do we need RECIST for quality of life to achieve standardization? Qual Life Res 24: 5-18.

Babchia N, Calipel A, Mouriaux F, Faussat A-M, Mascarelli F (2008) 17-AAG and 17-DMAG-induced inhibition of cell proliferation through B-Raf downregulation in WT B-Raf-expressing uveal melanoma cell lines. Invest Ophthalmol Vis Sci 49: 2348-2356.

Berger AM, Mooney K, Alvarez-Perez A, Breitbart WS, Carpenter KM, Cella D, Cleeland C, Dotan E, Eisenberger MA, Escalante CP, Jacobsen PB, Jankowski C, LeBlanc T, Ligibel JA, Loggers ET, Mandrell B, Murphy BA, Palesh O, Pirl WF, Plaxe SC, Riba MB, Rugo HS, Salvador C, Wagner LI, Wagner-Johnston ND, Zachariah FJ, Bergman MA, Smith C (2015) Cancer-related fatigue, Version 2.2015. J Natl Compr Cancer Netw 13: 1012-1039.

Bhatia S, Moon J, Margolin KA, Weber JS, Lao CD, Othus M, Aparicio AM, Ribas A, Sondak VK (2012) Phase II trial of sorafenib in combination with carboplatin and paclitaxel in patients with metastatic uveal melanoma: SWOG S0512. PLoS ONE 7: e48787.

Calipel A, Lefevre G, Pouponnot C, Mouriaux F, Eychène A, Mascarelli F (2003) Mutation of B-Raf in human choroidal melanoma cells mediates cell proliferation and transformation through the MEK/ERK pathway. J Biol Chem 278: 42409-42418.

Carvajal RD, Sosman JA, Quevedo JF, Milhem MM, Joshua AM, Kudchadkar RR, Linette GP, Gajewski TF, Lutzky J, Lawson DH, Lao CD, Flynn PJ, Albertini MR, Sato T, Lewis K, Doyle A, Ancell K, Panageas KS, Bluth M, Hedvat C, Erinjeri J, Ambrosini G, Marr B, Abramson DH, Dickson MA, Wolchok JD, Chapman PB, Schwartz GK (2014) Effect of selumetinib vs chemotherapy on progression-free survival in uveal melanoma: a randomized clinical trial. JAMA 311: 2397-2405.

Cella DF, Tulsky DS, Gray G, Sarafian B, Linn E, Bonomi A, Silberman M, Yellen SB, Winicour P, Brannon J (1993) The Functional Assessment of Cancer Therapy scale: development and validation of the general measure. J Clin Oncol 11: 570-579.

Dancey JE, Dodd LE, Ford R, Kaplan R, Mooney M, Rubinstein L, Schwartz LH, Shankar L, Therasse P (2009) Recommendations for the assessment of progression in randomised cancer treatment trials. Eur J Cancer 45: 281-289.

Di Marco V, De Vita F, Koskinas J, Semela D, Toniutto P, Verslype C (2013) Sorafenib: from literature to clinical practice. Ann Oncol 24: ii30-ii37.

Escudier B, Eisen T, Stadler WM, Szczylik C, Oudard S, Staehler M, Negrier S, Chevreau C, Desai AA, Rolland F, Demkow T, Hutson TE, Gore M, Anderson S, Hofilena G, Shan M, Pena C, Lathia C, Bukowski RM (2009) Sorafenib for treatment of renal cell carcinoma: final efficacy and safety results of the phase III treatment approaches in renal cancer global evaluation trial. J Clin Oncol 27: 3312-3318.

Gragoudas ES, Egan KM, Seddon JM, Glynn RJ, Walsh SM, Finn SM, Munzenrider JE, Spar MD (1991) Survival of patients with metastases from uveal melanoma. Ophthalmology 98: 383-389discussion 390.

Korn EL, Dodd LE, Freidlin B (2010) Measurement error in the timing of events: effect on survival analyses in randomized clinical trials. Clin Trials 7: 626-633.

Kujala E, Makitie T, Kivela T (2003) Very long-term prognosis of patients with malignant uveal melanoma. Invest Ophthalmol Vis Sci 44: 4651-4659.

Larkin JMG, Pyle LM, Gore ME (2010) Fatigue in renal cell carcinoma: the hidden burden of current targeted therapies. Oncologist 15: $1135-1146$

Mahipal A, Tijani L, Chan K, Laudadio M, Mastrangelo MJ, Sato T (2012) A pilot study of sunitinib malate in patients with metastatic uveal melanoma. Melanoma Res 22: 440-446.

Méndez-Vidal MJ, Martínez Ortega E, Montesa Pino A, Pérez Valderrama B, Viciana R (2012) Management of adverse events of targeted therapies in 
normal and special patients with metastatic renal cell carcinoma. Cancer Metastasis Rev 31(Suppl 1): S19-S27.

Mitsiades N, Chew SA, He B, Riechardt AI, Karadedou T, Kotoula V, Poulaki V (2011) Genotype-dependent sensitivity of uveal melanoma cell lines to inhibition of B-Raf, MEK, and Akt kinases: rationale for personalized therapy. Invest Ophthalmol Vis Sci 52: 7248-7255.

Osoba D, Zee B (1998) Completion rates in health-related quality-of-life assessment: approach of the National Cancer Institute of Canada Clinical Trials Group. Stat Med 17: 603-612.

Smets EM, Garssen B, Bonke B, De Haes JC (1995) The Multidimensional Fatigue Inventory (MFI) psychometric qualities of an instrument to assess fatigue. J Psychosom Res 39: 315-325.
Wilson MK, Karakasis K, Oza AM (2015) Outcomes and endpoints in trials of cancer treatment: the past, present, and future. Lancet Oncol 16: e32-e42.

Woodman SE (2012) Metastatic uveal melanoma: biology and emerging treatments. Cancer J 18: 148-152.

This work is published under the standard license to publish agreement. After 12 months the work will become freely available and the license terms will switch to a Creative Commons AttributionNonCommercial-Share Alike 4.0 Unported License.

Supplementary Information accompanies this paper on British Journal of Cancer website (http://www.nature.com/bjc) 